\title{
CORRECTION
}

\section{Correction to: A Global Survey of Disease Burden in Patients Who Carry a Diagnosis of Chronic Inflammatory Demyelinating Polyneuropathy}

Jeffrey A. Allen $\cdot$ Lisa Butler $\cdot$ Todd Levine $\cdot$ Anne Haudrich

Published online: January 13, 2021

(C) The Author(s) 2021

Correction to: Adv Ther

https://doi.org/10.1007/s12325-020-01540-6

The original article is published with few errors in Table 3, Fig. 2 and Fig. 3. The correct Table 3, Fig. 2 and Fig. 3 are given below.

The original article can be found online at https://doi. org/10.1007/s12325-020-01540-6.

J. A. Allen ( $\square)$

Department of Neurology, University of Minnesota,

Minneapolis, MN, USA

e-mail: jaallen@umn.edu

L. Butler

GBS/CIDP Foundation International,

Conshohocken, PA, USA

T. Levine

Phoenix Neurological Associates, Phoenix, AZ, USA

A. Haudrich

CSL Behring, King of Prussia, PA, USA 
Table 3 Demographics of survey respondents

\begin{tabular}{|c|c|c|c|}
\hline & Global, likely CIDP $(n=222)$ & $\begin{array}{l}\text { Global, somewhat likely } \\
\text { CIDP }(n=204)\end{array}$ & $\begin{array}{l}\text { Global, unlikely } \\
\text { CIDP }(n=169)\end{array}$ \\
\hline Sex, male, \% & 46 & 39 & 51 \\
\hline \multicolumn{4}{|l|}{ Age (at diagnosis), $n$ (\%) } \\
\hline$\leq 29$ & $15(6.76)$ & $16(7.84)$ & $9(5.33)$ \\
\hline $30-39$ & $32(14.41)$ & $35(17.16)$ & $19(11.24)$ \\
\hline $40-49$ & $46(20.72)$ & $50(24.51)$ & $30(17.75)$ \\
\hline $50-59$ & $69(31.01)$ & $63(30.88)$ & $49(28.99)$ \\
\hline $60-69$ & $47(21.17)$ & $29(14.22)$ & $41(24.26)$ \\
\hline $70-79$ & $12(5.41)^{*}$ & $10(4.9)$ & $20(11.83)^{*}$ \\
\hline$\geq 80$ & $1(0.45)$ & $1(0.49)$ & $1(0.59)$ \\
\hline \multicolumn{4}{|l|}{ Employment status (at diagnosis), \% } \\
\hline Employed & 71 & 68 & 59 \\
\hline Paid full-time & 61 & 63 & 51 \\
\hline Paid part-time & 10 & 5 & 8 \\
\hline Retired & 11 & 7 & 20 \\
\hline Student & 2 & 3 & 2 \\
\hline On disability & 6 & 10 & 8 \\
\hline Unemployed & 5 & 4 & 5 \\
\hline Other/unpaid work & 5 & 7 & 6 \\
\hline \multicolumn{4}{|c|}{ Current treatment at survey completion, \% } \\
\hline IVIg & 61 & 61 & 59 \\
\hline SCIg & 2 & 3 & 2 \\
\hline Corticosteroids & 23 & 22 & 15 \\
\hline IVIg and steroids & 12 & 14 & 9 \\
\hline Other immunosuppressive drugs & 15 & 17 & 18 \\
\hline Plasma exchange & 3 & 2 & 2 \\
\hline
\end{tabular}

IVIg intravenous immunoglobulin, SCIg subcutaneous immunoglobulin

* Statistically significantly different determined by $95 \%$ confidence intervals and $z$ tests 


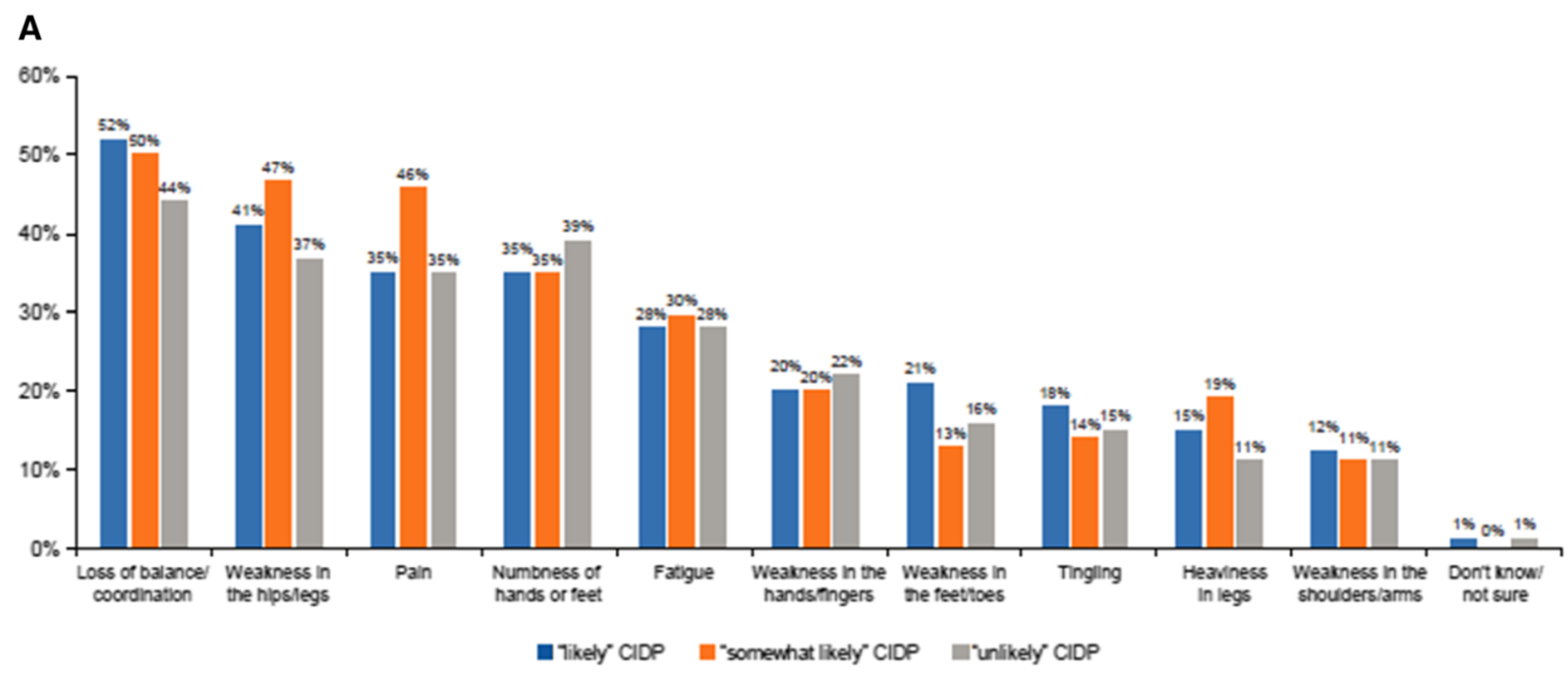

B

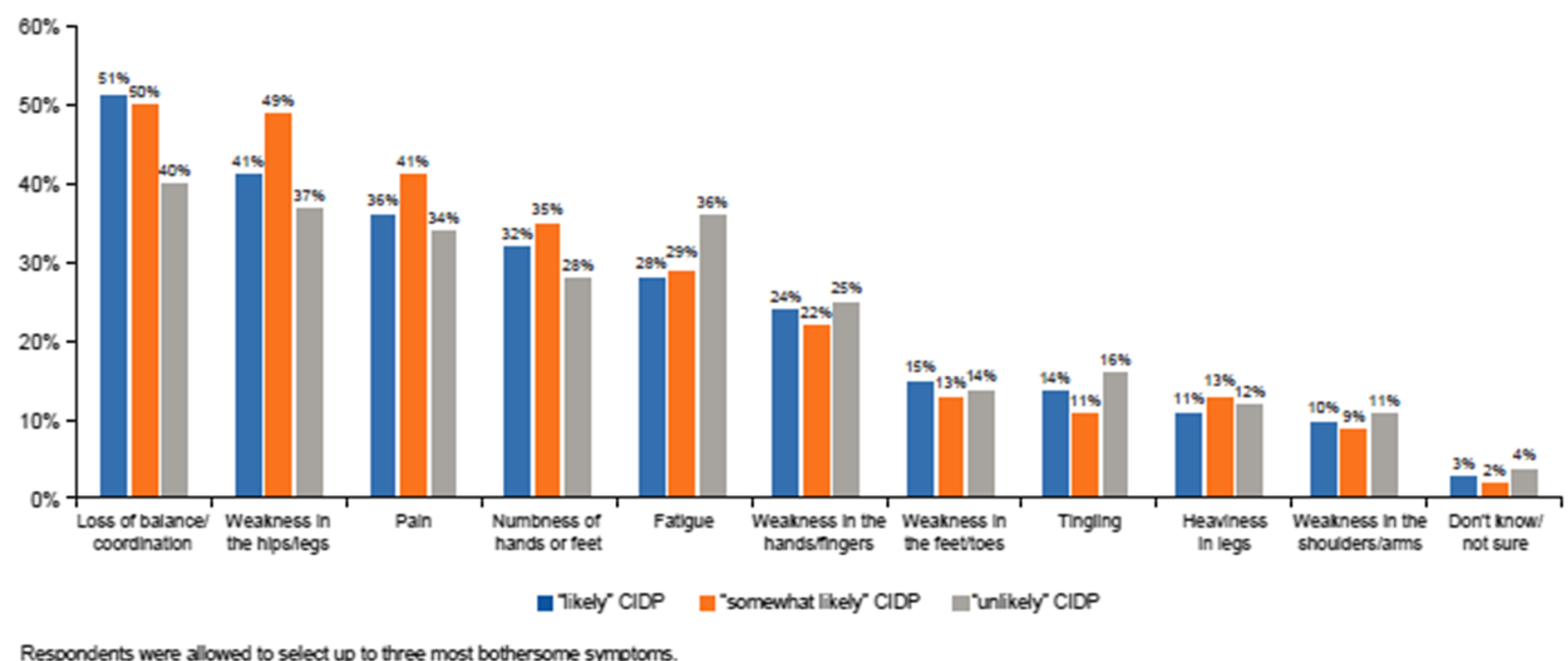

Fig. 2 Most bothersome symptoms when treatment started (a) and symptoms they most wanted relief from currently (b) 


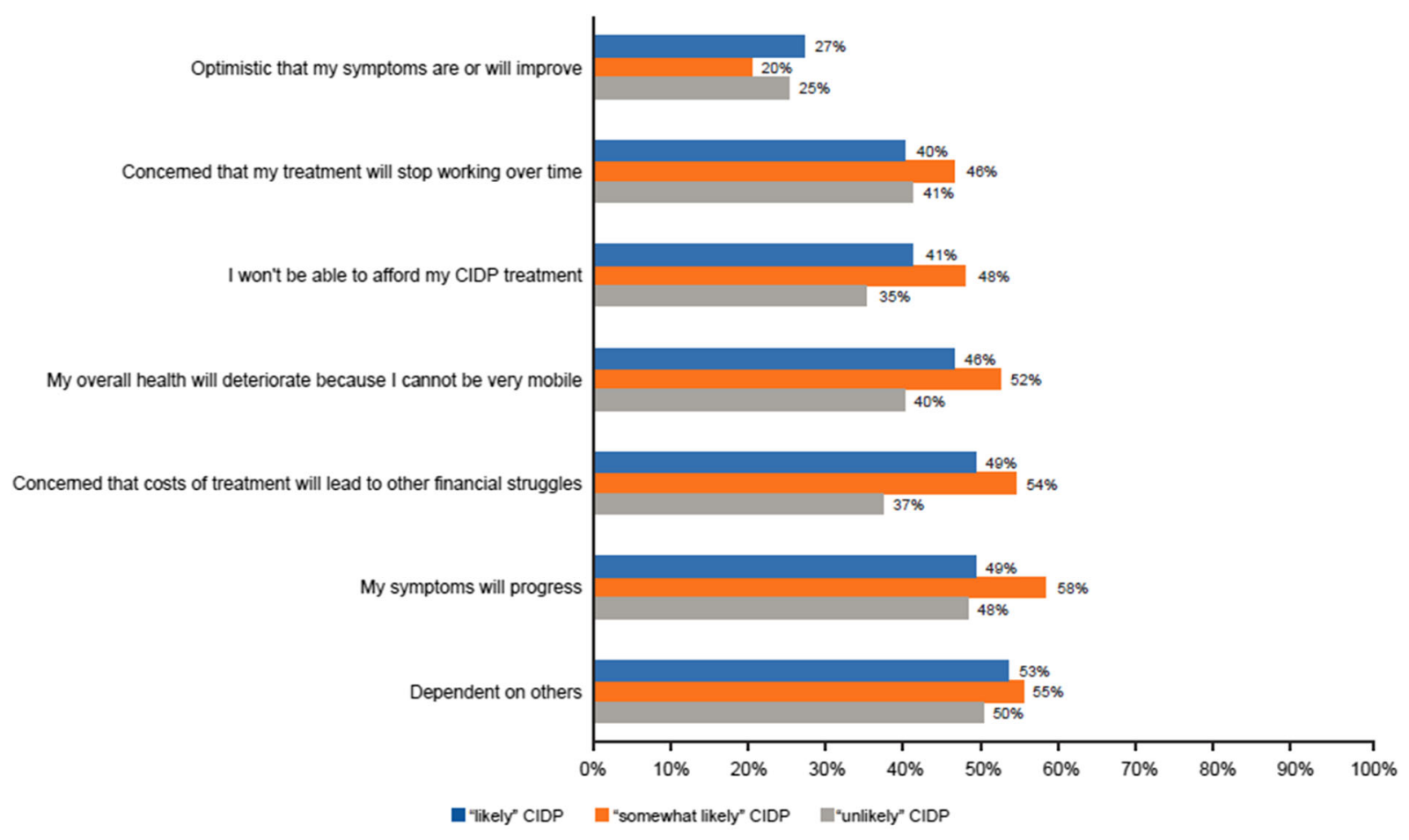

*Respondent options: Never, Rarely, Sometimes, Often, Always. $\mathrm{N}=593$ for questions 'I won't be able to afford by CIDP treatment' and 'Concerned that costs of treatment will lead to other financial struggles', all other questions $\mathrm{N}=595$.

Fig. 3 Survey responses of "always" or "often"* on feelings about their future

The original article has been corrected.

Open Access. This article is licensed under a Creative Commons Attribution-NonCommercial 4.0 International License, which permits any non-commercial use, sharing, adaptation, distribution and reproduction in any medium or format, as long as you give appropriate credit to the original author(s) and the source, provide a link to the Creative Commons licence, and indicate if changes were made. The images or other third party material in this article are included in the article's Creative Commons licence, unless indicated otherwise in a credit line to the material. If material is not included in the article's Creative Commons licence and your intended use is not permitted by statutory regulation or exceeds the permitted use, you will need to obtain permission directly from the copyright holder. To view a copy of this licence, visit http://creativecommons.org/licenses/bync/4.0/. 